\title{
Berufsanerkennung und Dienstleistungen im europäischen Binnenmarkt
}

Die EU-Richtlinien aus der Perspektive der Methodik der Rechtsangleichung und des Wettbewerbs der Rechtsordnungen

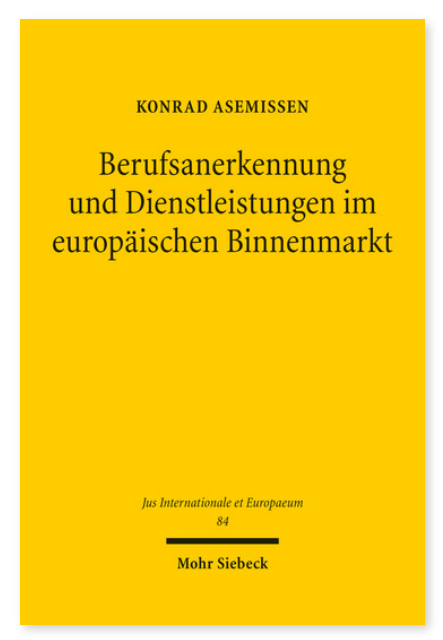

2014. XV, 359 Seiten. JusIntEu 84

ISBN 978-3-16-153155-2

DOI 10.1628/978-3-16-153155-2

eBook PDF 94,00€

ISBN 978-3-16-153044-9

fadengeheftete Broschur $94,00 €$
Die Berufsanerkennungs- und die Dienstleistungsrichtlinie sind die zentralen Rechtsakte zur Vertiefung des europäischen Binnenmarktes im Bereich der Dienstleistungen. Kontroverse Diskussionen im Rechtssetzungsverfahren haben den gemeinsamen Kontext der Richtlinien jedoch verschwimmen lassen. Konrad Asemissen stellt die Richtlinien nun als einheitlichen Regelungszusammenhang dar. Auf der Grundlage der Regulierungsmethodik der binnenmarktfinalen Rechtsangleichung untersucht er den regulatorischen Ansatz der Richtlinien, klärt ihr Verhältnis zueinander und bewertet die Kohärenz dieses Regulierungskonzeptes für den Dienstleistungssektor. Er geht schließlich der Frage nach, inwiefern die Richtlinien den Wettbewerb der Rechtsordnungen zu fördern vermögen. Ausgehend vom System des Wettbewerbs der Rechtsordnungen widmet sich der Autor auch dem Phänomen der Inländerdiskriminierung.

Konrad Asemissen Geboren 1984; Studium der Rechtswissenschaften in Bayreuth, Genf und Münster; 2013 Promotion; seit Februar 2012 Rechtsreferendariat am Kammergericht Berlin.

Jetzt bestellen:

https://mohrsiebeck.com/buch/berufsanerkennung-und-dienstleistungen-im-europaeischen-binnenmarkt-9783161531552? no_cache=1

order@mohrsiebeck.com

Telefon: +49 (0)7071-923-17

Telefax: +49 (0)7071-51104 